Document downloaded from:

http://hdl.handle.net/10251/46784

This paper must be cited as:

Catalá Icardo, M.; López Paz, JL.; Pérez Plancha, LM. (2014). Fast determination of thiacloprid by photoinduced chemiluminescence. Applied Spectroscopy. 68(6):642-648. doi:10.1366/13-07330.

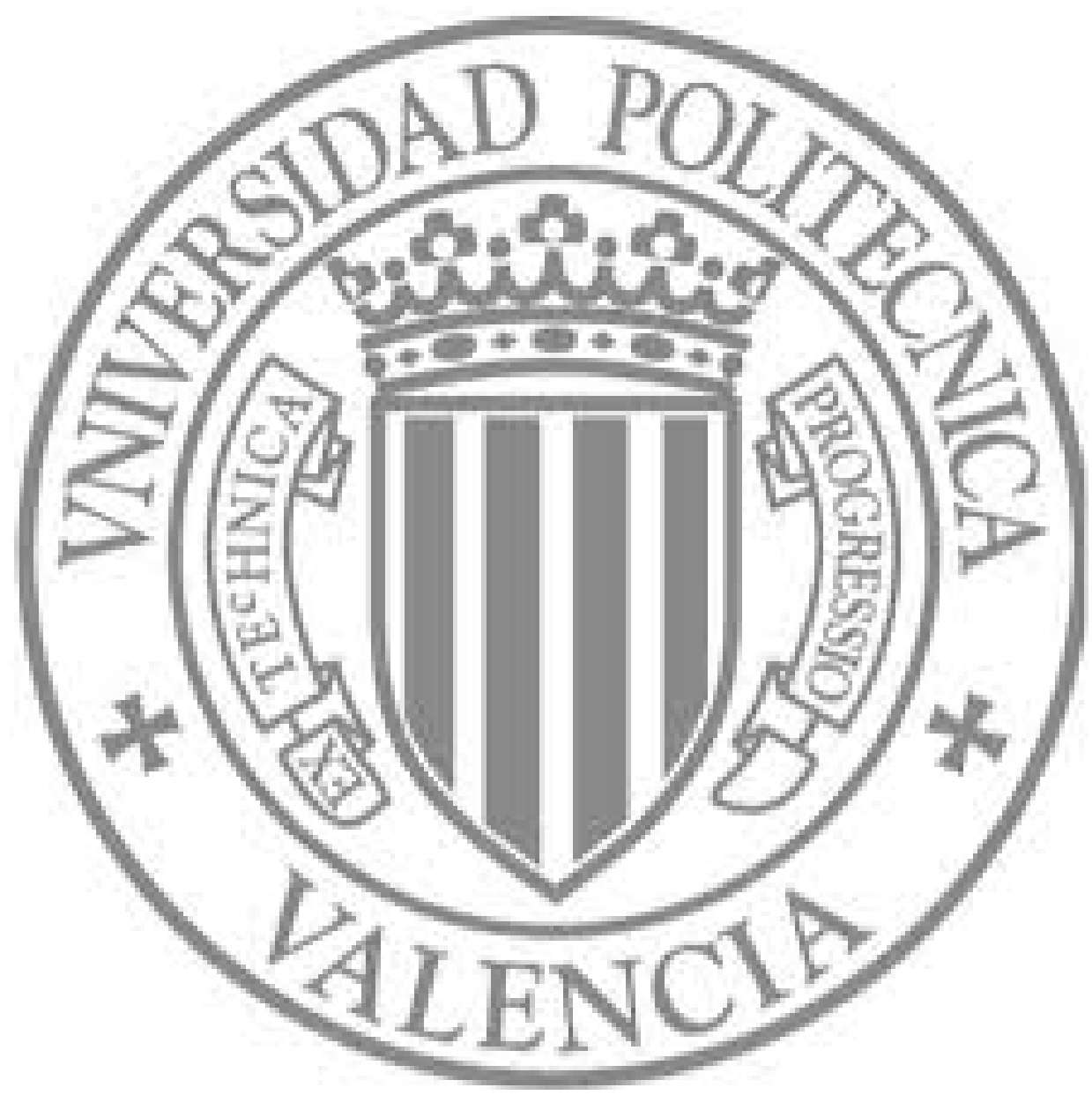

The final publication is available at

http://www.opticsinfobase.org/as/abstract.cfm?URI=as-68-6-642

Copyright Society for Applied Spectroscopy 


\title{
Fast determination of thiacloprid by photoinduced chemiluminescence
}

Mónica Catalá-Icardo ${ }^{\mathrm{a}^{*}}$, José Luis López-Paz ${ }^{\mathrm{b}}$ Laura María Pérez-Plancha ${ }^{\mathrm{a}}$

${ }^{a}$ Instituto de Investigación para la Gestión Integrada de Zonas Costeras (IGIC). Universitat Politècnica de València. C/ Paranimf n ${ }^{\circ}$, 46730 Grao de Gandía, Valencia, Spain.

${ }^{b}$ Centro de Reconocimiento Molecular y Desarrollo Tecnológico (IDM). Universitat Politècnica de València. Camino de Vera s/n, 46022 Valencia, Spain.

* Corresponding author. Tel. +34 9628493 33; fax: +34 9628493 09. E-mail address: mocaic@qim.upv.es (M. Catalá-Icardo)

\begin{abstract}
A new and sensitive application of the chemiluminescence detection has been developed for the determination of the pesticide thiacloprid in water. It was based on the on-line photoreaction of thiacloprid in basic medium, with quinine acting as sensitizer of the chemiluminescent response; Cerium (IV) in sulfuric acid medium was used as oxidant. A high automation and reproducibility was provided by a flow injection analysis (FIA) manifold. The validation of the method was performed in terms of selectivity, linearity, LOD, precision and accuracy. Liquid chromatography with UV detection was used as reference for mineral, tap, ground and spring water samples. The proposed method is fast (throughput of $130 \mathrm{~h}^{-1}$ ), sensitive (LOD of $0.8 \mathrm{ng} \mathrm{mL} \mathrm{L}^{-1}$ without preconcentration steps and $0.08 \mathrm{ng} \mathrm{mL}^{-1}$ with solid phase extraction (SPE)), low-cost and possible to couple with separative methods for the simultaneous determination of other pesticides. The enhanced chemiluminescence intensity was linear with thiacloprid concentration over the (2-80) and (80-800) $\mathrm{ng} \mathrm{mL}^{-1}$ ranges. A possible reaction mechanism is also discussed.
\end{abstract}

Keywords: thiacloprid; chemiluminescence; photoreaction; flow injection; water; solid phase extraction. 


\section{Introduction}

Thiacloprid ([3-[(6-chloro-3-pyridinyl)methyl]-2-thiazolidinylidene]cyanamide) (Fig. 1) is a neonicotinoid insecticide used against a variety of sucking insects in cotton and pome fruits. It is a relatively new pesticide (patent 1985) ${ }^{1}$, which is a disruptor of the nervous system by acting as an inhibitor at nicotinic acetylcholine receptors found in many insects ${ }^{2}$. The possible relationship between neonicotinoid pesticides and massive disappearance of honeybees from the hive is a topic of great interest nowadays ${ }^{3-4}$. Despite of the specific toxicity of thiachloprid for insects, it is dangerous to humans. Its relatively high water solubility results in the potential contamination of surface water, especially considering its resistance to photo- and biodecomposition in aqueous solutions ${ }^{5}$.

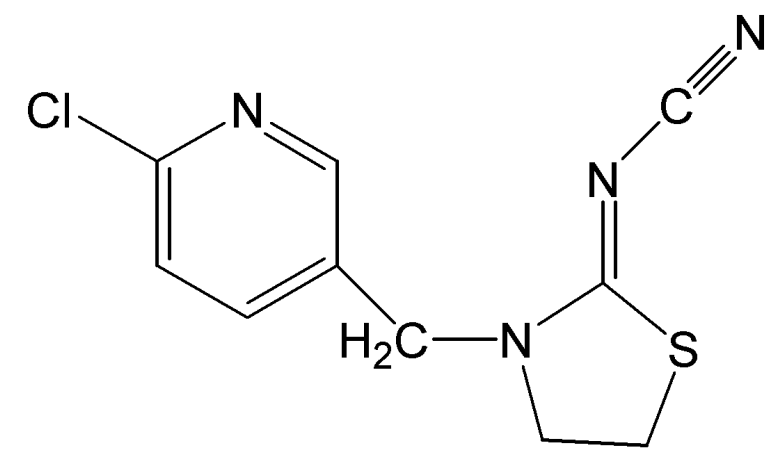

Fig. 1 Molecular structure of thiacloprid

Due to its low volatility, liquid chromatography (LC) is more commonly used than gas chromatography (GC) for the determination of thiacloprid. Mass spectrometer $(\mathrm{MS})^{6-11}$ is the most used detector with LC, although diode-array detection ${ }^{12-14}$ has been also proposed. Many methods have been developed for the determination of neonicotinoids residues in food, but only few of them are devoted to their analysis in water samples ${ }^{9}$. On the other hand, it is usually necessary to carry out previous preconcentration and clean-up steps, since pesticides are present at low concentrations in samples.

However, despite to be the most usual method for thiacloprid determination, LCMS is an expensive technique which is not always available as a routine analytical method. Therefore, the development of other strategies is mandatory, and a variety of alternative detection systems has been recently proposed for its determination ${ }^{15-16}$. 
Chemiluminescence (CL) is a powerful analytical tool applied in the last years in a wide variety of disciplines, due to its high sensitivity, selectivity, wide dynamic range simplicity and low cost instrumentation ${ }^{17-18}$. Most of the proposed CL methods are based on the luminol system ${ }^{18-20}$, although direct CL determination with strong oxidants (e.g., permanganate, cerium (IV), hexacyanoferrate (III) or periodate) have been also employed $^{18,21}$. These last systems are simpler and involve light emission from the reaction between a suitable oxidant and the target analyte, which is the substrate in the CL reaction $^{22}$.

Additionally, the combination of the CL with photochemical reactions, produced by irradiation with UV light, has allowed the increase in the number of compounds that can be determined by CL and/or increase the efficiency in the CL reaction ${ }^{18,23-25}$. On the other hand, flow injection analysis (FIA) is an important alternative to more complex procedures due to its simplicity and low cost. In addition, its rapidity and reproducibility makes it well suited to monitoring transient light emission from CL reactions, and allows the easy on-line photoreaction. To the authors' knowledge, until now no method based on CL or FIA has been previously reported for thiacloprid determination.

This paper reports a simple, economic and sensitive method based on the photoinduced chemiluminescence (PICL) technique for thiacloprid determination, fast enough for use in routine analyses, which is particularly suitable for environmental water control. The Ce(IV)-sulfuric acid system allowed obtaining an emitting molecule from a thiacloprid photoproduct, with quinine acting as sensitizer. Although the method has been developed using FIA methodology, it could be easily coupled with a LC system since both techniques operate in a continuous flow. This combination would be highly promising, as it would offer the selectivity necessary to implement the proposed method to more complex environmental samples.

\section{Materials and methods}

Chemicals

All solutions were prepared from analytical-grade reagents in Milli-Q water (18 $\mathrm{M} \Omega-\mathrm{cm}$ ) from Millipore (Bedford, MA, USA), provided with a $0.22 \mu \mathrm{m}$ fiber filter. Thiacloprid was purchased from Riedel-de Haën (99.9\% purity) (Seelze, Germany). Other reagents were: $\mathrm{Ce}\left(\mathrm{NH}_{4}\right)_{2}\left(\mathrm{NO}_{3}\right)_{6}$, from Panreac (Barcelona, Spain); $\mathrm{NaOH}$ and 
$\mathrm{H}_{2} \mathrm{SO}_{4}$ from Scharlau (Barcelona, Spain); and quinine hydrochloride dihydrate from Sigma (Steinheim, Germany). Other pesticides used were: acetamiprid, imidacloprid, amitrole, metazachlor, metalaxyl and cyromazine (99.9\%), 2,4-D and pirimicarb (99.6\%), diquat monohydrate (99.4\%), glyphosate and quinmerac (99.2\%), fenamiphos (97.7\%), diuron (99.5\%), imazalil (99.8\%) and MCPA (98.7\%) all of them from Riedelde Haën; methomyl (99.5\%) from Chem Service (West Chester, USA); and, diphenamide (99.9\%) from Fluka (Buchs, Switzerland).

The solid phase extraction (SPE) of water samples was carried out using Strata$\mathrm{X}$ (polymeric reversed phase) $200 \mathrm{mg} / 6 \mathrm{~mL}$ cartridges from Phenomenex (Torrance, CA, USA).

Flow injection procedure

The FIA manifold optimized for the PICL determination of thiacloprid is depicted in Fig. 2. Connections between the different parts of the flow assembly were carried out with PTFE coil of $0.8 \mathrm{~mm}$ i.d. from Omnifit. Gilson (Worthington, OH, USA) Minipuls 2 peristaltic pumps, provided with tygon pump tubes from Restec (Barcelona, Spain), were used for flow control. The laboratory-made photoreactor consisted of PTFE tubing $(0.8 \mathrm{~mm}$ i.d. $\times 400 \mathrm{~cm})$ tightly coiled around a $15 \mathrm{~W}$ low-pressure mercury lamp (Sylvania) for germicidal use. The samples were injected by a 4-way rotatory valve Model 5041 (Rheodyne, Wertheim-Mondfeld, Germany). The photodetector package was a P30CWAD5F-29 Type 9125 photomultiplier tube (PMT) supplied by Electron Tubes (Uxbridge, UK) operating at $1280 \mathrm{~V}$ and located in a laboratory-made light-tight box. The solutions merged in a T-piece placed inside close to the flow-cell, a flat-spiral glass tube of $1 \mathrm{~mm}$ i.d. and $3 \mathrm{~cm}$ total diameter. The output was fed to a computer equipped with a CT2 counter-timer board, also supplied by Electron Tubes. 


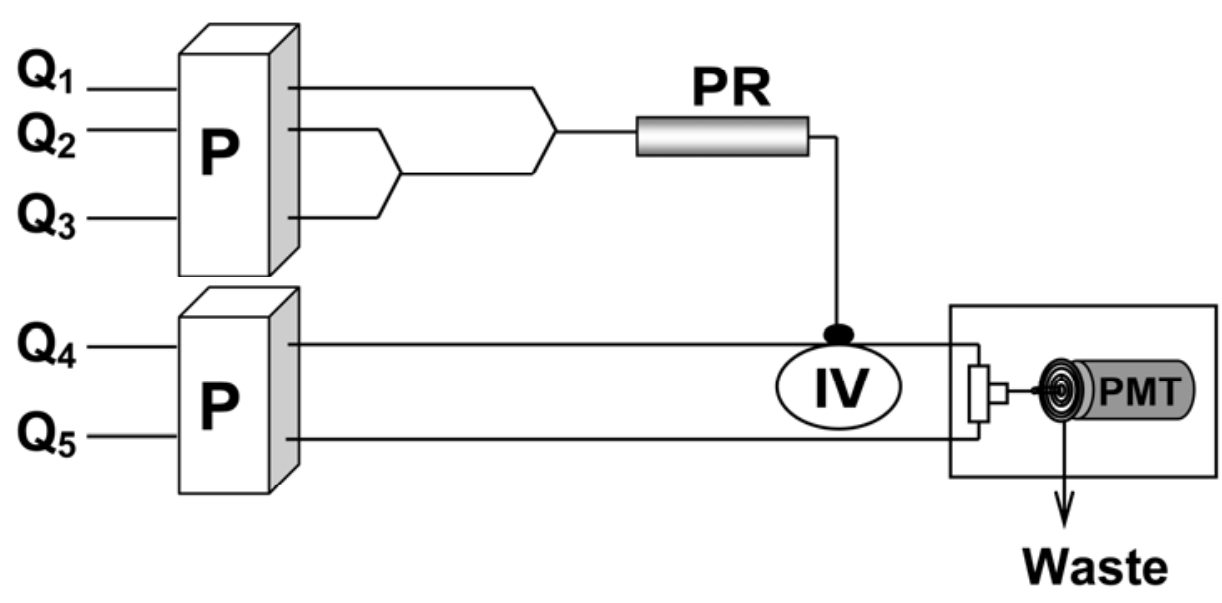

Fig. 2 Flow assembly for the PICL determination of thiacloprid. $\mathrm{Q}_{1}$ : thiacloprid solution at $1.85 \mathrm{~mL} \mathrm{~min}^{-1} ; \mathrm{Q}_{2}$ : $\mathrm{NaOH} 0.15 \mathrm{M}$ at $0.5 \mathrm{~mL} \mathrm{~min}^{-1} ; \mathrm{Q}_{3}$ : quinine $2 \times 10^{-5} \mathrm{M}$ at $0.5 \mathrm{~mL}$ $\min ^{-1}$; $\mathrm{Q}_{4}: \mathrm{H}_{2} \mathrm{O}$ at $11.4 \mathrm{~mL} \mathrm{~min}^{-1}$; $\mathrm{Q}_{5}: \mathrm{Ce}(\mathrm{IV}) 10^{-3} \mathrm{M}$ in $\mathrm{H}_{2} \mathrm{SO}_{4} 0.07 \mathrm{M}$ at $2.6 \mathrm{~mL} \mathrm{~min}^{-1}$. Injection volume: $583 \mu \mathrm{L}$. P: peristaltic pump; PR: photoreactor; IV: Injection valve; PMT: photomultiplier tube

Sample preparation

Water samples from different origins, namely ground, spring, mineral and tap waters were tested. They were collected in plastic flaks at $4{ }^{\circ} \mathrm{C}$ and analysed within 48 h. Prior to analysis, samples were pretreated by filtering over a $0.45 \mu \mathrm{m}$ membrane filter (Sartorius, Goettongen, Germany). $100 \mathrm{~mL}$ of sample was spiked in order to obtain 0.5 , $1.0,1.5,2.0$ and $2.5 \mathrm{ng} \mathrm{mL}^{-1}$ of pesticide.

In order to obtain a 20 -fold pre-concentration, SPE of $100 \mathrm{~mL}$ of the spiked samples was performed off-line at $3 \mathrm{~mL} \mathrm{~min}^{-1}$ using a vacuum system and Strata-X cartridges. $6.0 \mathrm{~mL}$ of methanol followed by $9.0 \mathrm{~mL}$ of water were used to precondition the cartridges. After that, the washing was performed with $9.0 \mathrm{~mL}$ of water and, next, air was passed 15 min for drying. Thiacloprid was eluted by means of gravity with 3.0 $\mathrm{mL}$ of methanol and finally under vacuum. The residue was evaporated to dryness under a gentle stream of nitrogen in a water bath at $30^{\circ} \mathrm{C}$; finally it was dissolved with $5.0 \mathrm{~mL}$ of water. 
Reference method

LC in combination with a diode-array detector (DAD) was used as a reference for sample analysis and validation of the proposed method. After the above-mentioned SPE procedure, the aliquots of sample were filtered through $0.22 \mu \mathrm{m}$ syringe filters. The mobile phase consisted of a mixture of water and acetonitrile $(75: 25, \mathrm{v} / \mathrm{v})$. The reversed phase separation was performed in the isocratic mode at a flow rate of $0.8 \mathrm{~mL} \mathrm{~min}{ }^{-1}$. A Kinetex C18 100 x $4.6 \mathrm{~mm}(2.6 \mu \mathrm{m}$ particle size) column from Phenomenex, in conjunction with a security guard UHPLC C18 from Jasco Analítica (Madrid, Spain), was used. Chromatographic analysis was carried out with a HPLC equipment from Jasco Analytica. $100 \mu \mathrm{L}$ of sample, in $25 \%$ of acetonitrile, was injected and the determination was performed at $240 \mathrm{~nm}$. The retention time was $5.6 \mathrm{~min}$ and the peak area was used for analytical purposes.

\section{Results and discussion}

Method development

\section{Preliminary studies}

Thiacloprid did not show CL properties when oxidized by common oxidants. However, it is well known that UV irradiation can induce reactions of photolysis, photocyclization, photoisomerization, photooxidation or photoreduction ${ }^{24}$; the photoproducts obtained often exhibit luminescent properties, which is the basis of PICL methods. Since the absorption spectrum of thiacloprid (200-380 $\mathrm{nm}$ with a maximum at $\left.242 \mathrm{~nm}^{26}\right)$ and the emission spectrum of the low-pressure Hg lamp (200-300 nm, with a maximum at $254 \mathrm{~nm}^{24}$ ) employed overlap, thiacloprid was considered to be a good candidate to generate PICL.

To study the PICL of thiacloprid, a FIA manifold on the basic lines of that shown in Fig. 2, but without channel $\mathrm{Q}_{3}$ and with an additional channel (oxidant medium) that converges with $\mathrm{Q}_{5}$ (oxidant), was used. Perchlorate $8 \times 10^{-3} \mathrm{M}$ in basic medium and nine oxidants commonly used in CL systems ${ }^{24}$ were employed at the following flow rates $\left(\mathrm{mL} \mathrm{min}^{-1}\right): 7.8$ for carrier, 1.2 for oxidant and oxidant media, 2.1 for thiacloprid and 0.65 for photodegradation media. As a result, a strong CL emission 
(17.6 kHz) was observed for $10 \mu \mathrm{gL}^{-1}$ of thiacloprid when $\mathrm{Ce}(\mathrm{IV})$ was used as oxidant in sulfuric acid medium, employing $0.1 \mathrm{M} \mathrm{NaOH}$ as irradiation medium. On the other hand, permanganate in acid medium, and ferricyanide and periodate in basic medium, also provided significant CL signals (about $3 \mathrm{kHz}$ ), when basic medium was used for irradiation, but lower than that reported for $\mathrm{Ce}(\mathrm{IV})$.

\section{Optimization process}

Optimization process was performed by using the univariate approach and optimal values were selected considering the sensitivity, reproducibility, blank outputs and signal/noise ratio.

The first aim was to find the best oxidant system for PICL determination of thiacloprid. The four oxidants above-mentioned were tested at different concentrations, namely (optimal value between brackets) $3 \times 10^{-3}-7 \times 10^{-3} \mathrm{M}\left(5 \times 10^{-3} \mathrm{M}\right)$ for $\mathrm{Ce}(\mathrm{IV}), 2 \times 10^{-}$ ${ }^{5}-9 \times 10^{-4} \mathrm{M}\left(6 \times 10^{-5} \mathrm{M}\right)$ for permanganate, $10^{-5}-10^{-2} \mathrm{M}\left(6 \times 10^{-5} \mathrm{M}\right)$ for ferricyanide, and, $2 \times 10^{-3}-2 \times 10^{-2} \mathrm{M}\left(1.5 \times 10^{-2} \mathrm{M}\right)$ for periodate. The highest signals were found for $\mathrm{Ce}(\mathrm{IV})$ and permanganate (about $5 \mathrm{kHz}$ for $3 \mu \mathrm{g} \mathrm{mL}^{-1}$ of thiacloprid in both cases). Therefore, the effect of different oxidation media was studied for both oxidants. As shown in Fig. 3 , sulfuric, perchlorate and nitric acids were the best option in both cases. Finally, it was found that $\mathrm{Ce}(\mathrm{IV})$ in sulfuric acid $0.08 \mathrm{M}$ was the best oxidant system (outputs two-fold higher than those from permanganate were obtained).

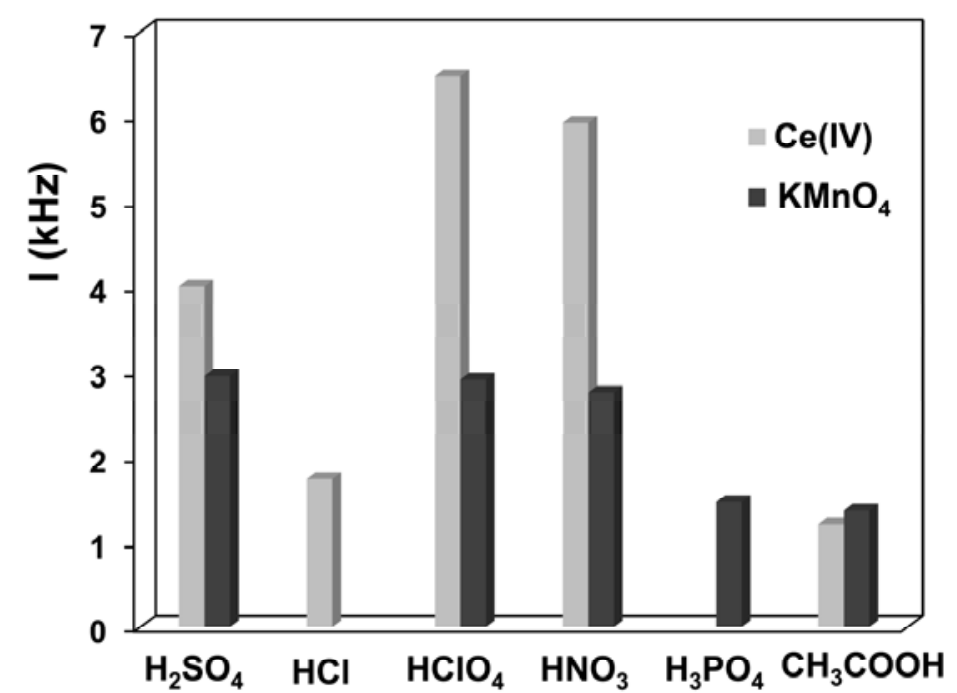

Fig. 3 CL signal obtained with $\mathrm{Ce}(\mathrm{IV})$ and permanganate in several acid media $(1 \mathrm{M})$ 
The effect of the oxidation time was investigated by changing simultaneously the carrier and oxidant system (Ce(IV) and sulfuric acid) flow rates within the $6.6-$ $11.8 \mathrm{~mL} \mathrm{~min}^{-1}$ range, keeping their ratio constant. As a result, 7.5 and $1.7 \mathrm{~mL} \mathrm{~min}^{-1}$ were found as the optimal flow rates for carrier and oxidant system, respectively.

Bearing in mind that it was difficult to test the effect of sulfuric acid (oxidant medium) and sodium hydroxide (irradiation medium) on $\mathrm{pH}$ independently, different buffers were assayed for the CL reaction medium, namely glycine- $\mathrm{HCl}(\mathrm{pH} 1.2$ and 2), ftalate $(\mathrm{pH} 2.4$ and 3.2), and acetic/acetate $(\mathrm{pH} 4)$. Citrate and tartrate buffers were discarded because of their negative effect on the baseline. As a result, it was found that only glycine buffer at $\mathrm{pH} 1.2$ provided similar results to those previously obtained with sulfuric acid. Therefore, the effect of irradiation media was studied using both, sulfuric acid and glycine buffer, as oxidation media. Taking into account the obtained results in preliminary studies, $\mathrm{NaOH}$ and $\mathrm{H}_{2} \mathrm{SO}_{4}$ were assayed as irradiation media. $\mathrm{NaOH}$ led to higher outputs (40\% improvement) in both oxidation media. Consequently, $\mathrm{NaOH} 0.1$ $\mathrm{M}$ and sulfuric acid were finally selected as irradiation and oxidation media, respectively.

Next, several compounds described in the literature ${ }^{27}$ as potential CL enhancers were examined. To this end, the manifolds were modified being the configurations employed as the basic lines showed in Fig. 2, but with an additional Y-shaped piece after the lamp, in order to study the effect of the studied substances, both in the photoreaction and CL reaction or only in the CL reaction.

The following substances were tested: ethanol, acetone, acetonitrile, a mixture of acetonitrile and acetone, 2-propanol, 1,4-dioxane, formic acid, sodium sulfite, quinine, 8-hydroxyquinoline, fluorescein, rhodamine B, riboflavin, acridin orange, hydrogen peroxide, $\beta$-cyclodextrin, sodium dodecyl sulfate, hexadecyltrimethylammonium bromide and Triton X-100.

As quinine, sulfite and riboflavin provided the highest signals, their effect on the CL emission was further studied over the $\left(4.7 \times 10^{-5}-9.3 \times 10^{-4}\right),\left(10^{-5}-2 \times 10^{-4}\right)$ and $\left(10^{-5}-\right.$ $10^{-3}$ ) $M$ ranges respectively, both before and after the irradiation step. Sulfite and 
quinine provided similar results, and better than riboflavin. However, sulfite was discarded due to its higher blank signals and lower stability. Finally, a concentration of $9.3 \times 10^{-5} \mathrm{M}$ of quinine, introduced before the irradiation step, was selected (6.5-fold increase).

Quinine has been often employed with $\mathrm{Ce}(\mathrm{IV})$ in order to increase the CL intensity, by an energy-transfer excitation process. The reduction of $\mathrm{Ce}$ (IV) would produce excited $\mathrm{Ce}(\mathrm{III})$, which is deactivated by emitting light of $350 \mathrm{~nm}$ yielding a weak CL signal ${ }^{28-32}$. Quinine is a good fluorescent substance $(\Phi=0.577)$ having an emission maximum at about $450 \mathrm{~nm}^{33}$. Excited Ce(III) would transfer energy to quinine yielding excited quinine, which would be responsible for the strong CL observed.

The photoproduct obtained and the yield of the photodegradation step are strongly dependent on irradiation time. Because of that, this parameter was studied by changing the sample, irradiation medium $(\mathrm{NaOH})$ and sensitizer (quinine) flow rates simultaneously, keeping their ratio constant. As can be seen in fig. 4, irradiation times between 39 and 48 s provided the best result. A dramatic decrease in the CL emission was observed with longer irradiation times, which was probably due to the formation of a non-CL photoproduct. Consequently, an irradiation time of $42 \mathrm{~s}$ was selected, which corresponded to $1.85 \mathrm{~mL} \mathrm{~min}^{-1}$ for sample and $0.5 \mathrm{~mL} \mathrm{~min}{ }^{-1}$ for both, $\mathrm{NaOH}$ and quinine.

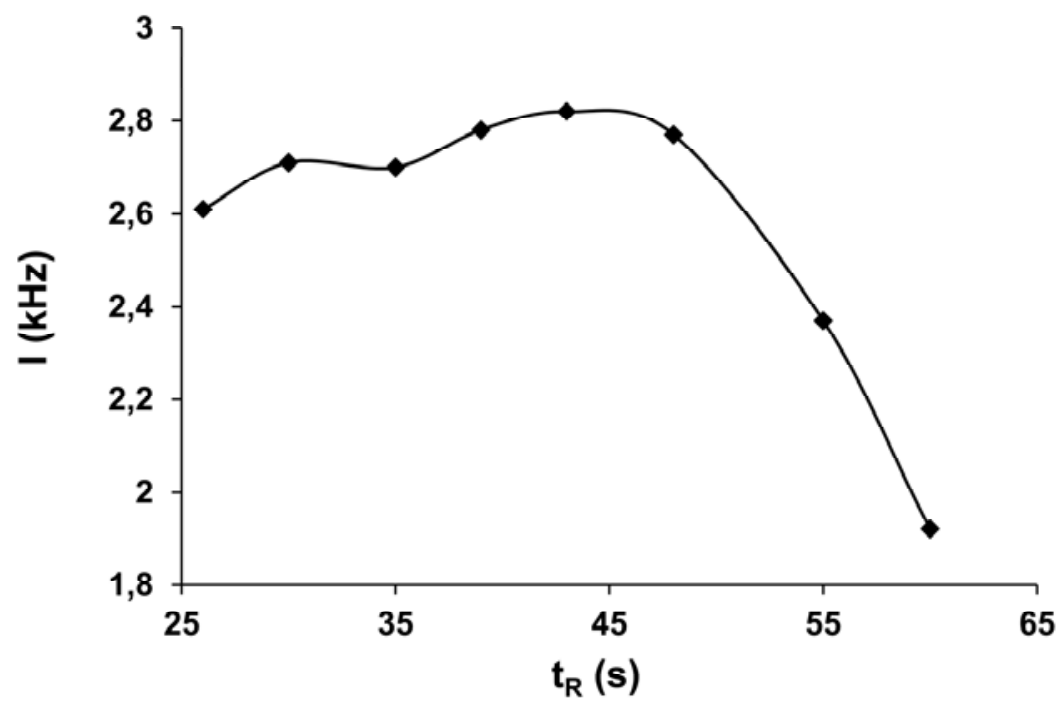

Fig. 4 Effect of irradiation time $\left(t_{R}\right)$ on CL signal 
Bearing in mind that high temperatures can influence on oxidation rate, the sample loop and two $1.5 \mathrm{~m}$ sections of teflon tube $(0.8 \mathrm{~mm}$ i.d.), containing the carrier (located immediately prior to the injection valve to minimize sample dispersion) and the oxidant, were submerged in a water bath at different temperatures. A slight increase of signal $(+17 \%)$ was observed when temperature increased until $50{ }^{\circ} \mathrm{C}$ and, after that, signals decreased. Taking into account the small improvement achieved, room temperature was selected in order to have a simpler manifold.

The insertion volume was the last parameter optimized, testing values between 398 and $675 \mu \mathrm{L}$. The signal reached a plateau at $583 \mu \mathrm{L}$; therefore, this value was selected for further investigation.

Finally, bearing in mind the results achieved in the optimization step, the main variables were re-optimized using the following ranges (optimal results in brackets) (see Fig. S5 in Electronic Supplementary Material): Ce(IV): $2 \times 10^{-4}-5.5 \times 10^{-3} \mathrm{M}\left(10^{-3} \mathrm{M}\right)$; sulfuric acid: $0.05-0.10 \mathrm{M}(0.07 \mathrm{M})$; global flow rate in CL reaction: $8.3-15.4 \mathrm{~mL} \mathrm{~min}^{-1}$ (14 $\mathrm{mL} \mathrm{min}$ min $^{-1}$ corresponding to 11.4 and $2.6 \mathrm{~mL} \mathrm{~min}^{-1}$ for carrier and oxidant respectively); $\mathrm{NaOH}$ : $0.13-0.19 \mathrm{M}(0.15 \mathrm{M})$; quinine: $2 \times 10^{-6}-10^{-4} \mathrm{M}\left(2 \times 10^{-5} \mathrm{M}\right)$; and, irradiation time: $32-60 \mathrm{~s}$ (42 s; sample flowing at $1.85 \mathrm{~mL} \mathrm{~min}^{-1}$ and $\mathrm{NaOH}$ and quinine at $\left.0.5 \mathrm{~mL} \mathrm{~min}^{-1}\right)$.

\section{Validation}

The dependence between CL signal and thiacloprid concentration was linear and two different linear ranges were found (Fig. 5). The corresponding equations average, calculated from five calibrations obtained on different days with fresh solutions were: I= $(0.0470 \pm 0.0011) \mathrm{C}+(0.14 \pm 0.04)$ with $\mathrm{r}^{2}=0.995$ for thiacloprid concentrations ranging from 2 to $80 \mathrm{ng} \mathrm{mL} L^{-1}$; and $\mathrm{I}=(0.0107 \pm 0.0005) \cdot \mathrm{C}+(3.3 \pm 0.5)$ with $\mathrm{r}^{2}=0.996$, for pesticide concentrations from 80 to $800 \mathrm{ng} \mathrm{mL}$; where $\mathrm{I}$ is the intensity $(\mathrm{kHz})$ and $\mathrm{C}$ the concentration $\left(\mathrm{ng} \mathrm{mL} \mathrm{mL}^{-1}\right)$ 


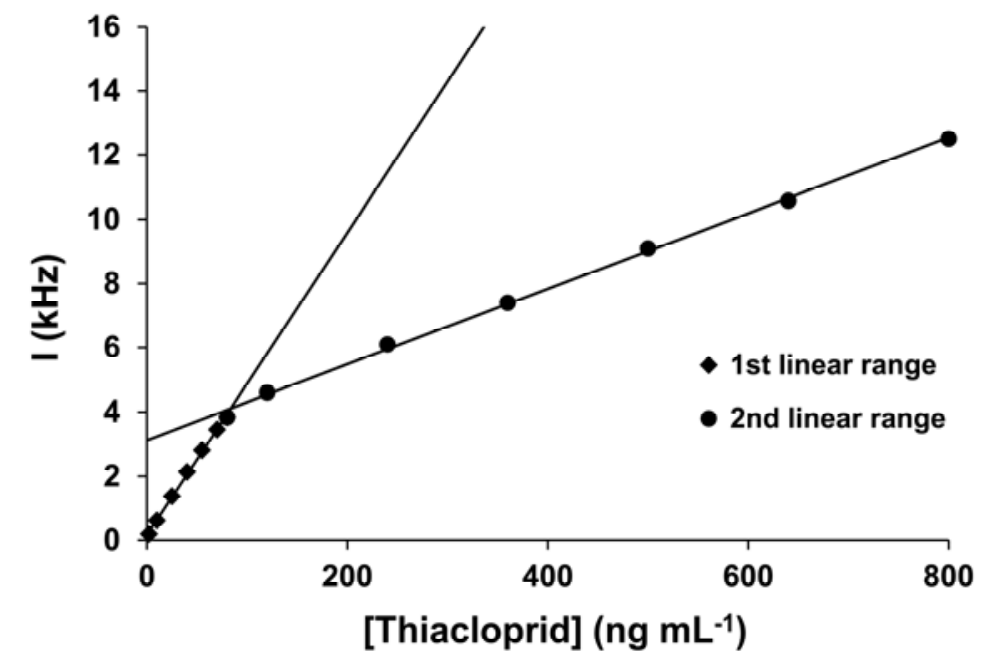

Fig. 5 Influence of thiacloprid concentration on the CL signal.

1st linear range: $2-80 \mathrm{ng} \mathrm{mL}^{-1}$

2nd linear range: $80-800 \mathrm{ng} \mathrm{mL^{-1 }}$

The limit of detection (LOD), defined as the lowest thiacloprid concentration giving a signal equal or greater than the blank peak plus three times its standard deviation (SD), was experimentally determined and took a value of $0.8 \mathrm{ng} \mathrm{mL}^{-1}$. The inter-day reproducibility of the proposed method was determined from the slopes of the abovementioned series of 5 calibrations. The relative standard deviation (RSD) were 2.3 and $4.7 \%$ for the first and second linear range, respectively. The intra-day repeatability, determined as the RSD of a series of 23 injections of $40 \mathrm{ng} \mathrm{mL} L^{-1}$ of thiacloprid, was $2.1 \%$. The throughput, calculated from the same series of peaks, was $130 \mathrm{~h}^{-1}$.

The interfering effect of the ions commonly present in natural waters at relevant concentrations was investigated in order to assess the tolerance of the proposed method (Table I). The effect of other pesticides from different chemical groups ${ }^{34}$ was also studied (Table II). The relative errors showed in both tables were obtained using $40 \mathrm{ng}$ $\mathrm{mL}^{-1}$ of thiacloprid as a reference. This study was carried out by reducing the concentration of interfering compounds until the relative error was below 5\%. As can be observed, some of the tested ions, namely $\mathrm{NO}_{3}{ }^{-}, \mathrm{NH}_{4}{ }^{+}, \mathrm{Mg}^{2+}, \mathrm{HCO}_{3}{ }^{-}$or $\mathrm{H}_{2} \mathrm{PO}_{4}{ }^{-}$, showed an important interfering effect. 
Table I Study of interfering species on thiacloprid $40 \mathrm{ng} \mathrm{mL}^{-1}$

\begin{tabular}{lcc}
\hline Interferent & Concentration $\left(\mu \mathrm{g} \mathrm{mL}^{-1}\right)$ & Error $(\%)$ \\
\hline $\mathrm{Na}^{+}$ & 480 & -2.5 \\
$\mathrm{~K}^{+}$ & 500 & -2.2 \\
$\mathrm{Ca}^{2+}$ & 800 & -3.2 \\
$\mathrm{Mg}^{2+}$ & 30 & -4.4 \\
$\mathrm{NH}_{4}{ }^{+}$ & 1 & -3.0 \\
$\mathrm{Cl}^{-}$ & $1415^{\mathrm{a}}$ & -3.2 \\
$\mathrm{SO}_{4}{ }^{2-}$ & $1000^{\mathrm{a}}$ & -2.5 \\
$\mathrm{CH}_{3} \mathrm{COO}^{-}$ & 20 & -5.0 \\
$\mathrm{H}_{2} \mathrm{PO}_{4}{ }^{-}$ & 30 & -4.9 \\
$\mathrm{HCO}_{3}{ }^{-}$ & 30 & -3.0 \\
$\mathrm{NO}_{3}{ }^{-}$ & 0.15 & -1.8 \\
$\mathrm{Urea}^{\mathrm{a}}$ & 80 & -2.6 \\
\hline $\mathrm{Maximum}^{2}$ concentration assayed
\end{tabular}

Table II Interfering effect of pesticides on thiacloprid $40 \mathrm{ng} \mathrm{mL}^{-1}$

\begin{tabular}{llcc}
\hline Common name & Chemical group & [pesticide]/[thiacloprid] & Error (\%) \\
\hline Acetamiprid & Neonicotinoid & 10 & -3.7 \\
Amitrole & Triazole & 10 & -2.8 \\
Cyromazine & Triazine & 10 & -0.1 \\
2,4-D & Alkylchlorophenoxy & 10 & +1.2 \\
Dimethoate & Organophosphate & 0.25 & +2.6 \\
Diphenamid & Alkanamide & 7.5 & -2.2 \\
Diquat monohydrate & Bipyridylium & 3.75 & -2.4 \\
Diuron & Phenylurea & 0.25 & -2.3 \\
Fenamiphos & Organophosphate & 0.25 & +1.1 \\
Glyphosate & Phosphonoglycine & 10 & +5.0 \\
Imazalil & Imidazole & 10 & -4.3 \\
Imidacloprid & Neonicotinoid & 0.175 & -4.3 \\
MCPA & Aryloxyalkanoic acid & 8.75 & +0.7 \\
Metalaxyl & Phenylamide & 2.5 & -1.8 \\
Metazachlor & Chloroacetamide & 5 & -3.2 \\
Methomyl & Carbamate & 0.25 & +4.8 \\
Pirimicarb & Carbamate & 10 & -5.0 \\
Quinmerac & Quinoline & 10 & -4.2 \\
\hline
\end{tabular}


A strong decrease in the CL was observed when nitrate was present. It has probably to do with the oxidant consumption of nitrite, obtained as a result of the photoreduction of nitrate by UV light ${ }^{35}$. Others ions can also influence, on the photodegradation and/or the oxidation steps. However, ionic interferences can be easily removed by SPE.

When the effect of other pesticides on the CL signal was tested, it was found that dimethoate, fenamiphos and methomyl showed a strong interfering effect. That result was expected, since an important CL response for the photoproducts of all of them when oxidized by cerium (IV) have been previously reported ${ }^{21,36-37}$. Bearing in mind that fact, the use of a separative technique, such as LC, prior to analysis should be advisable when those pesticides are together with thiacloprid; thus, apart from their separation, their simultaneous determination should be achieved. Other neonicotinoid pesticides did not provide CL signal under the experimental conditions, but they inhibited the CL signal of thiacloprid because of matrix effect. A strongest interfering effect was observed for imidacloprid, which has a chemical structure more similar to thiacloprid. Finally, the addition of diuron resulted in an important decrease of CL. Diuron photoproducts have been reported as chemiluminescent when oxidized ${ }^{38}$; although a different oxidant system was used (potassium ferricyanide in phosphate buffer at $\mathrm{pH} 11.5$ ) in that method, a slight $\mathrm{CL}$ with cerium was also reported, but the concentrations of oxidant needed were higher in that case. Consequently, the decrease in the CL observed should be probably due to a cerium consumption by diuron. Thus, the separative strategy above-mentioned should be also recommendable in order to avoid the oxidant consumption.

\section{Quantitative results}

In order to increase the selectivity and sensitivity of the method, SPE (Sample preparation section) was applied to mineral, tap, ground and spring water samples. As a result, a LOD of $0.08 \mathrm{ng} \mathrm{mL}^{-1}$ was achieved, which is under the maximum permitted

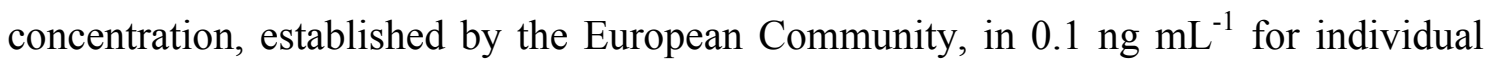
pesticides and $0.5 \mathrm{ng} \mathrm{mL}^{-1}$ for total pesticides in drinking water ${ }^{39}$ and $1-3 \mathrm{ng} \mathrm{mL}^{-1}$ in surface water ${ }^{40}$. For evaluating the accuracy of the method, the achieved results were compared with those obtained using HPLC-DAD (Reference Method section). 
As can be seen in Table III, mean recoveries ranging from 83.5 to $93.7 \%$ for samples spiked at five levels (between 0.5 and $2.5 \mathrm{ng} \mathrm{mL}^{-1}$ ) were achieved. Bearing in mind that the acceptable range for recoveries in water samples is usually set between 70 and $110 \%$, with a maximum permitted RSD of $20 \%{ }^{41}$, it can be considered that the analytical performance of the proposed CL method was successful. In addition, the results were in good agreement (88.5-96.3\%) with those obtained from HPLC.

Table III Accuracy of the method

\begin{tabular}{|c|c|c|c|c|c|}
\hline Sample & $\begin{array}{c}\text { Added } \\
\left(\mathrm{ng} \mathrm{mL} L^{-1}\right)\end{array}$ & $\begin{array}{c}\text { Found } \\
\text { FIA-PICL } \\
\left(\text { ng mL }{ }^{-1}\right)\end{array}$ & $\begin{array}{c}\text { Found } \\
\text { LC-DAD } \\
\left(\mathrm{ng} \mathrm{mL}^{-1}\right)\end{array}$ & $\begin{array}{c}\text { Recovery }(\%) \\
\text { FIA-PICL vs } \\
\text { added (RSD, \%) }\end{array}$ & $\begin{array}{l}\text { Recovery }(\%) \\
\text { FIA-PICL vs LC- } \\
\text { DAD (RSD, \%) }\end{array}$ \\
\hline \multirow[t]{5}{*}{ Mineral water $1^{\mathrm{a}}$} & 0.5 & 0.45 & 0.47 & $91.7(6.2)$ & $92.3(5.9)$ \\
\hline & 1.0 & 0.96 & 1.04 & & \\
\hline & 1.5 & 1.31 & 1.53 & & \\
\hline & 2.0 & 1.72 & 1.94 & & \\
\hline & 2.5 & 2.48 & 2.50 & & \\
\hline \multirow[t]{5}{*}{ Mineral water $2^{\mathrm{b}}$} & 0.5 & 0.44 & 0.49 & $88.0(7.1)$ & $90.0(3.9)$ \\
\hline & 1.0 & 0.80 & 0.91 & & \\
\hline & 1.5 & 1.45 & 1.52 & & \\
\hline & 2.0 & 1.81 & 2.00 & & \\
\hline & 2.5 & 2.12 & 2.46 & & \\
\hline \multirow[t]{5}{*}{ Tap water } & 0.5 & 0.39 & 0.44 & $83.5(9.9)$ & $89.6(8.7)$ \\
\hline & 1.0 & 0.85 & 0.91 & & \\
\hline & 1.5 & 1.23 & 1.44 & & \\
\hline & 2.0 & 1.51 & 1.89 & & \\
\hline & 2.5 & 2.42 & 2.41 & & \\
\hline \multirow[t]{5}{*}{ Ground water } & 0.5 & 0.43 & 0.50 & $85.6(7.2)$ & $88.5(5.8)$ \\
\hline & 1.0 & 0.81 & 0.96 & & \\
\hline & 1.5 & 1.43 & 1.50 & & \\
\hline & 2.0 & 1.59 & 1.89 & & \\
\hline & 2.5 & 2.16 & 2.33 & & \\
\hline \multirow[t]{5}{*}{ Spring water } & 0.5 & 0.42 & 0.46 & $93.7(8.4)$ & $96.3(5.9)$ \\
\hline & 1.0 & 0.91 & 0.97 & & \\
\hline & 1.5 & 1.54 & 1.51 & & \\
\hline & 2.0 & 1.80 & 1.97 & & \\
\hline & 2.5 & 2.52 & 2.45 & & \\
\hline
\end{tabular}

\footnotetext{
${ }^{\mathrm{a}}$ Soft water

${ }^{\mathrm{b}}$ Hard water
} 


\section{Conclusions}

A new and fast strategy has been proposed for thiacloprid determination in water samples. The method was based on the chemiluminescent reaction of its photoproducts with $\mathrm{Ce}(\mathrm{IV})$ in a sulfuric solution; the light emission being greatly sensitised by quinine.

The method could be implemented with SPE, in order to increase sensitivity and selectivity. The LODs achieved were: 0.08 and $0.8 \mathrm{ng} \mathrm{mL}^{-1}$ with and without SPE respectively. These values are competitive with those reported by most of methods used for the determination of thiacloprid in water samples. The LC-MS method proposed by Pareja et al. ${ }^{10}$, employing a hybrid triple quadrupole-linear ion trap-MS, allowed LODs as low as $0.002 \mathrm{ng} \mathrm{mL}^{-1}$; but in the LC-MS method reported by Seccia et al. ${ }^{9} \mathrm{SPE}$ of $1 \mathrm{~L}$ of sample was required in order to obtain a LOD of $0.01 \mathrm{ng} \mathrm{mL} \mathrm{mL}^{-1}$. Other recently published methods based on alternative methods ${ }^{15-16}$, provided LODs between 0.2-0.3 ng $\mathrm{mL}^{-1}$.

In summary, the proposed method has provided a high sensitivity and good recoveries when applied to water samples. It is simple, fast and cheap; moreover, it avoids the use of organic solvents and time consuming steps as filtration. Thus, it could be applied as a routine method for thiacloprid control in water samples. In addition, its coupling with separative techniques as LC would allow the simultaneous determination of other pesticides as dimethoate, fenamiphos and methomyl.

\section{Acknowledgements}

The authors would like to thank Ministerio de Educación y Ciencia from Spain and FEDER for financial support. Project CTM2006-11991.

\section{Supplementary material}

The supplementary material mentioned in the text includes six figures showing the effect of the parameters studied in the re-optimization step.

\section{References}

1. M. Tomizawa, J.E. Casida. "Neonicotinoid insecticide toxicology: Mechanisms of Selective Action". Annu. Rev. Pharmacol. Toxicol. 2005. 45:247-68. 
2. EPA. Environmental Protection Agency. Office of Prevention, Pesticides and Toxic Substances (7501C). United States. http://www.epa.gov/pesticides/chem_search/reg_actions/registration/fs_PC014019_26-Sep-03.pdf [accessed July 1 2013].

3. A. Tapparo, C. Giorio, L. Soldà, S. Bogialli, D. Marton, M. Marzano, V. Girolami. "UHPLC-DAD method for the determination of neonicotinoid insecticides in single bees and its relevance in honeybee colony loss investigations“. Anal. Bioanal. Chem. 2013. 405(2-3):1007-1014.

4. H.A. Tennekes, F. Sánchez-Bayo. "The molecular basis of simple relationships between exposure concentration and toxic effects with time". Toxicology. 2013. 309:39-51.

5. A. Peña, J.A. Rodríguez-Liébana, M.D. Mingorance. "Persistence of two neonicotinoid insecticides in wastewater, and in aqueous solutions of surfactants and dissolved organic matter". Chemosphere. 2011. 84(4):464-470.

6. W. Xie, Y. Qian, H.Y. Ding, X.M. Chen, J.Y. Xi, X.Y. Jiang. "Determination of six neonicotinoid pesticide residues in tea samples using high performance liquid chromatography tandem mass spectrometry". Fenxi Huaxue. 2009. 37(4):495499.

7. A. di Muccio, P. Fidente, D.A. Barbini, R. Dommarco, S. Seccia, P.J. Morrica. "Application of solid-phase extraction and liquid chromatography-mass spectrometry to the determination of neonicotinoid pesticide residues in fruit and vegetables". J. Chromatogr. A. 2006. 1108(1):1-6.

8. P. Fidente, S. Seccia, F. Vanni, P. Morrica. "Analysis of nicotinoid insecticides residues in honey by solid matrix partition clean-up and liquid chromatographyelectrospray mass spectrometry". J. Chromatogr. A. 2005. 1094(1-2):175-178.

9. S. Seccia, P. Fidente, D.A. Barbini, P. Morrica. "Multiresidue determination of nicotinoid insecticide residues in drinking water by liquid chromatography with electrospray ionization mass spectrometry". Anal. Chim. Acta. 2005. 553(1-2):2126.

10. L. Pareja, M.J. Martínez-Bueno, V. Cesio, H. Heinzen, A.R. Fernández-Alba. "Trace analysis of pesticides in paddy field water by direct injection using liquid chromatography-quadrupole-linear ion trap-mass spectrometry". J. Chromatogr. A. 2011. 1218(30):4790-4798.

11. D. Simedru, A. Naghiu, O. Cadar. "LC/MS/MS method for investigation of five pesticides from water". Studia UBB Chemia. 2012. 1:135-144.

12. R.Y. Hou, H.M. Cai, Z.Z. Zhang, X.C. Wang. "Determination of neonicotinoid pesticide residues in vegetables and fruits with high-performance liquid chromatography with diode-array detection". Fenxi Shiyanshi. 2010. 29(2): 59-63.

13. S. Seccia, P. Fidente, D. Montesano, P. Morrica. "Determination of neonicotinoid insecticides residues in bovine milk samples by solid-phase extraction clean-up and liquid chromatography with diode-array detection". J. Chromatogr. A. 2008. 1214(1-2):115-120.

14. W. Wang, Y. Li, Q. Wu, C. Wang, X. Zang, Z. Wang. "Extraction of neonicotinoid insecticides from environmental water samples with magnetic graphene nanoparticles as adsorbent followed by determination with HPLC". Anal. Methods. 2012. 4:766-772. 
15. M. Brycht, O. Vajdle, J. Zbiljić, Z. Papp, V. Guzsvány, S. Skrzypek. "Renewable silver-smalgam film electrode for direct cathodic SWV Ddetermination of clothianidin, nitenpyram and thiacloprid neonicotinoid insecticides reducible in a fairly negative potential range". Int. J. Electrochem. Sci. 2012. 7:10652-10665.

16. X. Y. Bi, K.L. Yang. "On-line monitoring imidacloprid and thiacloprid in celery juice using quartz crystal microbalance". Anal. Chem. 2009. 81(2):527-532.

17. L. Gámiz-Gracia, A.M. García-Campaña, J.J. Soto-Chinchilla, J.F. Huertas-Pérez, A. González-Casado. "Analysis of pesticides by chemiluminescence detection in the liquid phase". Trends Anal. Chem. 2005. 24(11):927-942.

18. A. Roda, M. Guardigli. "Analytical chemiluminescence and bioluminescence: Latest achievements and new horizons". Anal. Bioanal. Chem. 2012. 402(1):6976.

19. J. Du, H. Li. "Sensitive chemiluminescence determination of thirteen cephalosporin antibiotics with luminol-copper(II) reaction". Appl. Spectrosc. 2010. 64(10):1154-1159.

20. Y. Li, Y. Li, Y. Yang. "Flow-injection chemiluminescence determination of lisinopril using luminol- $\mathrm{KMnO}_{4}$ reaction catalyzed by silver nanoparticles". Appl. Spectrosc. 2011. 65(4):376-381.

21. M. Catalá-Icardo, J.L. López-Paz, C. Choves-Barón, A. Peña-Bádena. "Native vs photoinduced chemiluminescence in dimethoate determination". Anal. Chim. Acta. 2012. 710:81-87.

22. Y. Fuster Mestre, L. Lahuerta Zamora, J. Martínez Calatayud. "Flowchemiluminescence: a growing modality of pharmaceutical analysis". Luminescence. 2001. 16(3):213-235.

23. F.J. Lara, A.M. García-Campaña, J.J. Aaron. "Analytical applications of photoinduced chemiluminescence in flow systems - A review". Anal. Chim. Acta. 2010. 679(1-2):17-30.

24. M. Catalá Icardo, J. Martínez Calatayud. "Photo-induced luminescence". Crit. Rev. Anal. Chem. 2008. 38:118-130.

25. I. Sahuquillo Ricart, G.M. Antón-Fos, M.J. Duart, J.V. García Mateo, L. Lahuerta Zamora, J. Martínez Calatayud. "Theoretical prediction of the photoinduced chemiluminescence of pesticides". Talanta. 2007. 72:378-386.

26. B.F. Abramović, N.D. Banić, D.V. Šojić. "Degradation of thiacloprid in aqueous solution by UV and UV/ $\mathrm{H}_{2} \mathrm{O}_{2}$ treatments". Chemosphere. 2010. 81:114-119.

27. M. Catalá Icardo, M. Misiewicz, A. Ciucu, J.V. García Mateo, J. Martínez Calatayud. "FI-on line photochemical reaction for direct chemiluminescence determination of photodegradated chloramphenicol". Talanta. 2003. 60:405-414.

28. Y. Zhao, W.R.G. Baeyens, X. Zhang, A.C. Calokerinos, K. Nakashima, G. Van Der Weken. "Chemiluminescence Determination of Tiopronin by Flow Injection Analysis Based on Cerium(IV) Oxidation Sensitized by Quinine". Analyst. 1997. 122:103-106.

29. Z. Zhang, W.R.G. Baeyens, X. Zhang, Y. Zhao, G. Van Der Weken. "Chemiluminescence detection coupled to liquid chromatography for the 
determination of penicillamine in human urine". Anal. Chim. Acta. 1997. 347:325-332.

30. L.F. Capitán-Vallvey, M.C. Valencia Mirón, and R. Acosta Acosta. "Chemiluminescence determination of sodium 2-mercaptoethane sulfonate by flow injection analysis using cerium(IV) sensitized by quinine". Talanta. 2000. $51: 1155-1161$.

31. L. Nie, H. Ma, M. Sun, X, Li, M. Su, S. Liang. "Direct chemiluminescence determination of cysteine in human serum using quinine-Ce(IV) system". Talanta. 2003. 59(5):959-964.

32. A. Waseem, M. Yaqoob, A. Nabi. "Determination of thiram in natural waters using flow-injection with cerium(IV)-quinine chemiluminescence system". Luminescence. 2010. 25(1):71-75.

33. J.R. Lakowicz, "Principles of Fluorescence Spectroscopy". Springer, New York, 2006. 3rd ed.

34. International Union of Pure and Applied Chemistry. Global availability of information on agrochemicals. http://agrochemicals.iupac.org [accessed December 21 2012]

35. M. Lookabaugh, I.S. Krull. "Determination of nitrite and nitrate by reversedphase high-performance liquid chromatography using on-line post-column photolysis with ultraviolet absorbance and electrochemical detection". J. Chromatogr. A. 1988. 452:295-308.39.

36. J.L. Lopez-Paz, M. Catalá-Icardo, A. Langa-Sánchez. "Determination of methomyl by fl ow injection analysis with photoinduced chemiluminescence". Luminescence. 2010. 25:236-237.

37. C. Gómez-Benito, S. Meseguer-Lloret, S. Torres-Cartas. "Sensitive determination of Fenamiphos in water samples by flow injection photoinduced chemiluminescence". Int. J. Environ. Anal. Chem. 2013. 93(2): 152-165.

38. M. Catalá-Icardo, J.L. López-Paz, A. Peña-Bádena. "FI-photoinduced Chemiluminescence Method for Diuron Determination in Water Samples". Anal. Sci. 2011. 27:291-296.

39. European Union (98) Council Directive 98/83/EC of 3 November 1998 on the quality of water intended for human consumption. Off. J. Eur. Commun. 41, 5.12.98, L 330/42.

40. M. Fielding (Ed.) "Pesticides in Ground and Drinking Water. Water pollution research report 27". Commission of the European Communities, Brussels. 1991.

41. D.J. Hamilton, Á. Ambrus, R.M. Dieterle, A.S. Felsot, C.A. Harris, P.T. Holland, A. Katayama, N. Kurihara, J. Linders, J. Unsworth, S.S. Wong. "Regulatory Limits for Pesticide Residues in Water”. Pure Appl. Chem. 2003. 75:1123-1155. 